\title{
BASALTOS DA SUÍTE PARAPUÍ, GRÁBEN JAIBARAS, NOROESTE DO CEARÁ: CARACTERIZAÇÃO, PETROGRAFIA, GEOQUÍMICA E QUÍMICA MINERAL
}

\author{
ROSEMERY DA SILVA NASCIMENTO \& PAULO SERGIO DE SOUSA GORAYEB
}

\begin{abstract}
BASALTS OF THE PARAPUI SUITE, JAIBARAS GRABEN, NORTHWESTERN OF CEARÁ The Parapuí Suite is an important volcanic unit of the Jaibaras Graben, northwestern Ceará and represents an intense basalt volcanic activity during the Neoproterozoic/Eopaleozoic. Three main sequences are identified including basalts (labradorite/andesine basalts, trachybasalts and magnetite-ilmenite basalts), rhyolites and volcanoclastic rocks that occur intercalated with arkosian sandstones of the Jaibaras Group. The basalts and trachybasalts are the most abundant rock types in this Suite and occur as successions of large massive and amigdaloidal lava flows. They are holocrystalline or hypocrystalline, porphyritic or aphyric with flow structures. The main minerals are labradorite/andesine, titanoaugite and minor olivine, albite, sanidina, magnetite/ilmenite, pirite, titanite and apatite. The chemical signature is characterized by high contents of alkalis, $\mathrm{TiO}_{2}$ and $\mathrm{P}_{2} \mathrm{O}_{s}$, and enrichement in LREE with small negative Eu anomalies, high to moderate $(\mathrm{La} / \mathrm{Yb})_{\mathrm{N}}$ and $(\mathrm{Ti} / \mathrm{Y})_{\mathrm{N}}>1$. In discriminant diagrams they plot in the alkaline basalt and transitional to tholeitic fields. The tectonic setting is suggestive of an intraplate continental magmatism. Petrographic, geochemistry and field characteristics and discriminant diagrams define the basalts of Parapui Suite as result of an transitional basaltic series and their tectonic setting as continental within-plate.
\end{abstract}

Keywords: Volcanism, Transitional Basalts, Parapuí Suite, Jaibaras Graben, Northwestern Ceará, Borborema Province, Brazil

Resumo A Suíte Parapuí constitui uma unidade vulcânica, provavelmente do final do Neoproterozóico/inicio do Paleozóico que se encontra inserida no Gráben Jaibaras, situada no noroeste do Estado do Ceará, e representa uma importante atividade vulcânica basáltica, predominantemente, da porção noroeste da Província Borborema. A Suíte compreende três grupos de rochas, incluindo basaltos (labradorita/andesina basaltos, traquibasaltos e magnetita-ilmenita basaltos), riolitos e rochas vulcanoclásticas que ocorrem intercalados a arenitos arcosianos do Grupo Jaibaras, em que todo o conjunto acha-se afetado por incipiente metamorfismo. Os basaltos e traquibasaltos, tipos mais abundantes da Suite Parapuí, ocorrem em sucessões de extensos derrames de lavas maciças e amigdaloidais, com características holocristalinas, hipovítreas e raramente holovítreas, e texturas porfiríticas, seriadas ou afíricas e fluidais. Os minerais principais compreendem labradorita com variações para andesina, titanoaugita e subordinadamente, olivina, albita, sanidina, magnetita/ilmenita, pirita, titanita e apatita. Quimicamente apresentam altos teores de álcalis, $\mathrm{TiO}_{2}$ e $\mathrm{P}_{2} \mathrm{O}_{\varsigma}$, enriquecimento em ETR leves, pequenas anomalias negativas de Eu e $\mathrm{Nb}$, razão $(\mathrm{La} / \mathrm{Yb})_{N}$ moderada a alta e razão $(\mathrm{Ti} / \mathrm{Y})_{N}>1$, sugerindo derivação do manto litosférico. Nos diagramas classificatórios geoquímicos eles situam-se na transição entre os campos dos basaltos toleíticos e alcalinos, caracterizando uma série de basaltos transicionais. Nos diagramas multi-elementos apresentam assinatura geoquímica similar, o que revela a homogeneidade composicional desse magmatismo. Interpretações de paleoambiência tectônica são indicativas de magmatismo intraplaca continental associada a implantação do Gráben Jaibaras. A formação da Suíte Parapuí está relacionado à fase rifte do Gráben Jaibaras, cujos processos incluem intenso vulcanismo intracontinental num substrato paleoproterozóico da Província Borborema, em ambiente subaéreo, com efusões e explosões.

Palavras-chave: Vulcanismo, Basaltos Transicionais, Suíte Parapuí, Graben Jaibaras, Noroeste do Ceará, Província Borborema

INTRODUÇÃO Na região noroeste do Ceará, dentro do Sistema Médio Coreaú (Santos \& Neves 1984) destaca-se uma feição litoestrutural marcante de direção NNE-SSW, isolada em terrenos gnáissicos do Paleoproterozóico, denominada na literatura de Gráben Jaibaras. Nele ocorrem, intercaladas a uma sequência de rochas sedimentares fracamente metamorfizadas, uma sucessão de rochas vulcânicas relacionadas ao Neoproterozóico, reunidas no Grupo Jaibaras (Costa et al. 1979, Gorayeb et al. 1988). As rochas vulcânicas, objeto principal deste estudo, correspondem a basaltos, riolitos e rochas vulcanoclásticas que foram reunidas por Gorayeb et al. (1988) na Suite Parapuí e que representam um intenso vulcanismo ocorrido durante a implantação do Gráben Jaibaras.

Nos trabalhos do Projeto Jaibaras (Costa et al. 1979), este conjunto recebeu a denominação de Formação Parapuí, descrita como "basaltos, andesitos, dacitos e riolitos, geralmente espilitizados e queratofirizados, além de gabros, diabásios, dacitos e riolitos porfiríticos", e interpretada como uma suíte cálcico-alcalina (tipo Série Pacífica). Contudo, estudos posteriores de Sá et al. (1979), Nascimento et al. (1981) e Gorayeb \& Nascimento (1997), divergiram desta classificação e demonstraram que: a) os parâmetros geoquímicos utilizados por Costa et al. (1979) basearam-se em elementos móveis aos processos metassomáticos; b) a mineralogia reliquiar não corresponde a suítes cálcico-alcalinas; c) o caráter continental da bacia é incompatível com as características de suítes espilito-queratófiras, típicas de metassomatismo em fundo oceânico; d) as transformações presentes (albitização, propilitização) poderiam estar relacionadas a alterações hidrotermais pós-magmáticas ou ao metamorfismo e; e) foram incluídas uma série de litotipos de diferentes idades e origens não pertencentes a Suíte Parapuí.

O estudo envolveu levantamentos de campo ao longo das principais ocorrências dos corpos vulcânicos, por todo o Gráben Jaibaras (Fig. 1), com enfoque nas rochas basálticas, que constituem os principais litotipos de rochas da Suite Parapuí. Estudos petrográficos de detalhe foram realizados em mais de 100 amos- 
tras, complementados por análises químicas de minerais e rochas e interpretações sobre o magmatismo e ambiência tectônica.

\section{CONTEXTOGEOLÓGICODA SUÍTE PARAPUÍ Na região} noroeste do Ceará, domínio oeste da Província Borborema, o arcabouço geológico compreende três unidades geotectônicas principais. A unidade mais antiga, edificada no Paleoproterozóico e relacionada ao evento termo-tectônico Transamazônico (Gaudette et al. 1993), foi denominada por Abreu et al. (1988) de Cinturão de Cisalhamento Noroeste do Ceará. Esse Cinturão apre- senta estruturação principal na direção NE-SW e reúne um conjunto de granulitos, kinzigitos e gnaisses tonalíticos mais ou menos migmatizados (Complexo Granja) e sequências supracrustais (Grupo Martinópole) que foram estabilizados em condições metamórficas da fácies anfibolito alto a granulito (Gorayeb \& Abreu 1989, Abreu et al. 1989).

A segunda unidade, denominada Sistema Médio-Coreaú (Santos \& Neves 1984), edificada no Neoproterozóico, se sobrepõe à estruturação mais antiga na forma de grábens e horsts, tendo os principais traços de falhas dispostos na direção NE-SW, aprisio-

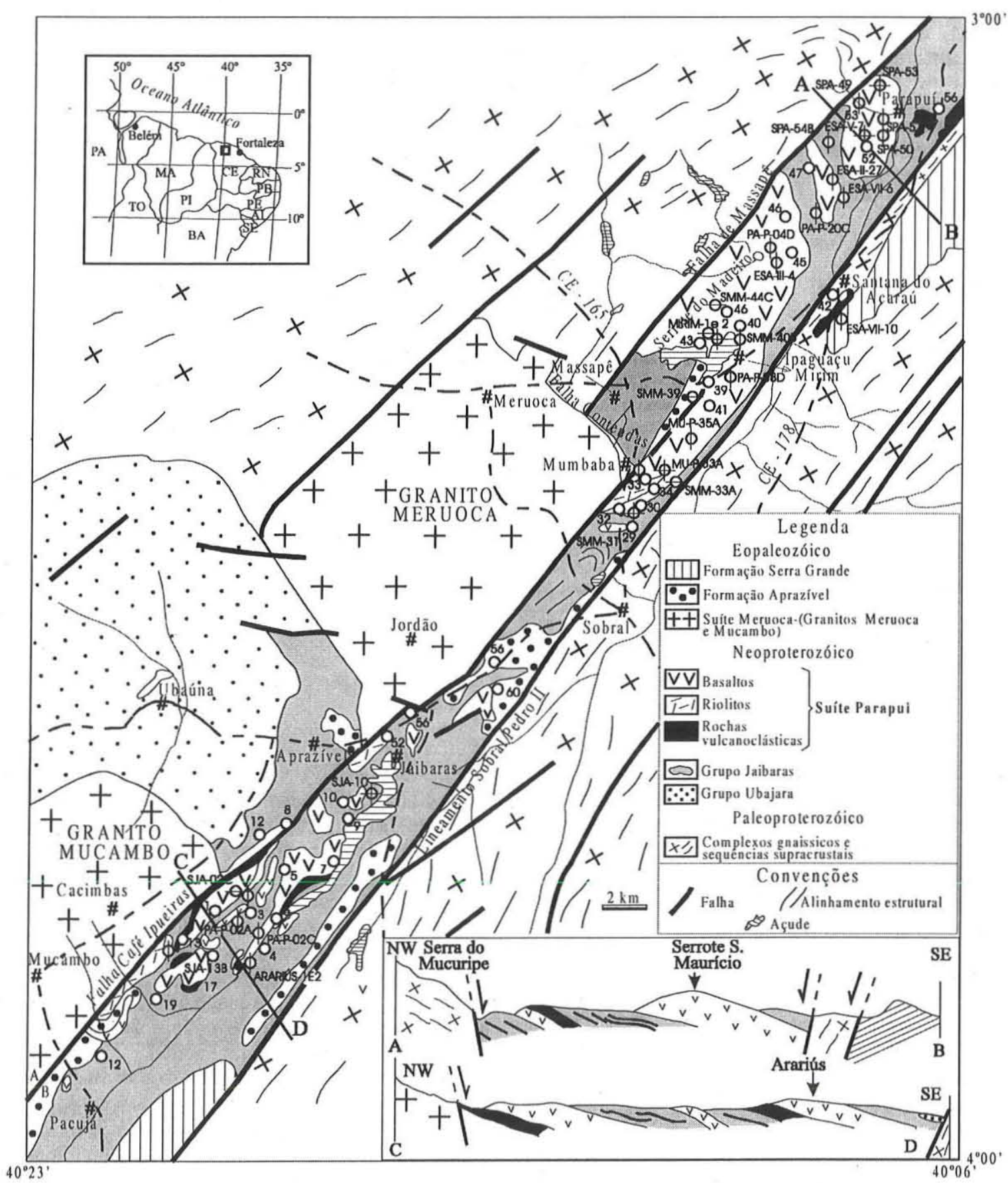

Figura 1 - Mapa geológico do Gráben Jaibaras com destaque às seqüências vulcânicas da Suite Parapuí e posicionamento das amostras estudadas. Base cartográfica a partir dos mapas geológicos de Costa et al. (1979). 
nando sequências de rochas vulcano-sedimentares, dentre as quais se inclui a Suíte Parapuí. Estas seqüências estão seccionadas por plutons graníticos do Eopaleozóico representados pelos granitos Meruoca e Mucambo (Gorayeb et al. 1988, 1993).

A terceira unidade corresponde a Bacia do Parnaíba que, na região, demarca a borda nordeste desta bacia, expondo suas unidades basais do Siluro-Devoniano.

Neste contexto a Suíte Parapuí está restrita a área do Gráben Jaibaras compreendendo uma sucessão de derrames de lavas basálticas e riolíticas com diversos depósitos piroclásticos (Fig. 1). A continuidade desses derrames para as áreas adjacentes (horsts) foi amplamente erodida, contudo, seus registros estão guardados nos depósitos sedimentares da Formação Aprazível que cobrem, em discordância erosiva, todo o conjunto de rochas mais antigas. Nos conglomerados desta formação estão presentes grandes quantidades de matacões e seixos dos vários tipos de rochas vulcânicas desta suíte, demonstrando a amplitude desse importante evento de vulcanismo do final do Proterozóico.

A Suíte Parapuí é constituída por grandes extensões de derrames de basaltos, traquibasaltos, riolitos mais restritos e depósitos de rochas vulcanoclásticas. Na porção meridional do Gráben Jaibaras os basaltos formam camadas de direção NE-SW com espessuras variando entre 40 e $60 \mathrm{~m}$ intercalados a arenitos arcosianos. Nesse caso a tendência geral das camadas é de basculamento para Ee SE, com valores de mergulho entre $15 \mathrm{e} 35^{\circ}$. A norte da Vila Jaibaras e na região de Mumbaba, os derrames são truncados pelo Granito Meruoca e são nítidas as relações de contato intrusivo, cujos efeitos térmicos transformaram as rochas vulcânicas e os sedimentos associados em hornfels. Tal situação está registrada no trecho da BR-222 entre Sobral e Aprazível, nos arredores da subestação da Embratel, e a sudeste da Vila Mumbaba. No bordo oeste do Granito Meruoca expressivos hornfels estão registrados sobre arenitos arcosianos e conglomerados (Gorayeb et al. 1988).

Na porção setentrional do Gráben Jaibaras ocorrem as maiores expressões areais e volumétricas das rochas vulcânicas da Suíte Parapuí sustentando os serrotes do Madeiro, do Morro, São Maurício e Mumbaba (Fig. 1). Nos três primeiros, com altitudes de 300400 m estão expostos sucessões de basaltos com espessuras da ordem de $250 \mathrm{~m}$, mergulhando suavemente para leste e sudeste. Já no Serrote Mumbaba, que ocorre entre as cidades de Sobral e Massapê, afloram derrames de riolitos com espessura da ordem de $150 \mathrm{~m}$, intercalados com basaltos e arcósios, mergulhando entre 30 e $45^{\circ}$ para SE. O Riolito Mumbaba projeta-se em direção a sudoeste, sendo truncado pelo Granito Meruoca, próximo a Vila Mumbaba, marcando pequena zona de hornfels, com neoformação de biotita e estilpnomelano nos riolitos.

As rochas vulcanoclásticas formam depósitos restritos e de espessura reduzida, embora às vezes ocupem extensas áreas, e geralmente ocorrem nas proximidades dos derrames basálticos. São constituídas por fragmentos de basalto, riolito oxidado, rochas sedimentares, bombas e outros fragmentos (lápili e cinza) e caracterizam depósitos epiclásticos e piroclásticos subaéreos.

PETROGRAFIA Os estudos petrográficos foram realizados em 115 lâminas delgadas provenientes de amostras do acervo de estágios de mapeamento do Curso de Graduação em Geologia da UFPA executados na região noroeste do Ceará nos anos de 1995 e 1996, e de amostras coletadas para este trabalho (Fig. 1).

Os resultados deste estudo revelaram a existência de três grupos principais de rochas vulcânicas, classificadas como labradorita/ andesina basaltos, traquibasaltos, riolitos e vulcanoclásticas.

Os basaltos, mais abundantes e de maior interesse ao presente trabalho, se classificam em 4 tipos principais, isto é, Labradorita/ Andesina Basalto, Olivina Basalto, Magnetita/Ilmenita Basalto e Traquibasalto. Considerando os aspectos texturais pode-se ainda ampliar os tipos em função da sua posição nos derrames, relacionado a cristalinidade ou ao ambiente vulcânico (porfiríticos, afíricos, seriados, vítreos, amigdaloidais, traquitóides, fragmental). Estruturas fluidais, brechas de fluxo, superfícies vítreas e zonas amigdaloidais podem ser freqüentes em limites de contato entre derrames. O preenchimento de amígdalas e poros compreendem clorita, zeólitas, carbonato, epidoto e raramente quartzo e prehnita.

Os basaltos são pretos, com variações para cinza escuro e castanho devido a alteração. São afaníticos, finos ou vítreos, holocristalinos ou hipovítreos. São comumente microporfiríticos com matriz intergranular ou intersertal. Seus constituintes essencias são plagioclásio e titanaugita, e os acessórios são titanita, ilmenita, pirita e apatita. Olivina e álcali-feldspato ocorrem ocasionalmente. Suas características petrográficas erão a seguir descritas.

Labradorita/Andesina Basaltos São os tipos vulcânicos predominantes na Suite Parapuí, constituindo rochas holocristalinas ou hipovítreas em que o plagioclásio de composição andesina/ labradorita $\left(\mathrm{An}_{46.50}\right)$ perfaz até $70 \%$ modal. Apresentam textura microporfirítica em que o plagioclásio forma microfenocristais tabulares, euédricos, envolvidos em matriz intergranular e intersertal. Micrólitos e cristalitos de plagioclásio e clinopiroxênio são freqüentes na matriz, envolvidos em material vítreo. Os microfenocristais de plagioclásio são euédricos, com maclamento polissintético e comprimento de até $2,5 \mathrm{~mm}$ e, freqüentemente, apresentam saussuritização parcial. O clinopiroxênio, identificado como titanoaugita varia entre 20 e $30 \%$ modal. Forma cristais aciculares e prismáticos, marrom-amarelado (X) a marromavermelhado (Y,Z). Em geral estão substituídos parcialmente por cristais fibrosos ou aciculares de tremolita-actinolita. Olivina ocorre raramente neste tipo composicional em quantidades traços, estando ausente na maioria das amostras. Outros minerais varietais tais como magnetita/ilmenita (ou titanomagnetita), e pirita atingem percentuais modais de até $10 \%$.

Olivina Basaltos São rochas holocristalinas ou hipovítreas que apresentam composição mineralógica semelhante ao tipo anterior, entretanto diferem pela presença de olivina que em algumas amostras atingem até $8 \%$ modal. A olivina ocorre como fenocristais euédricos ou em grânulos na matriz, com tamanhos de até $1,5 \mathrm{~mm}$. Os cristais de olivina estão fortemente fraturados e apresentam margens enegrecidas pela oxidação e extensiva transformação para serpentina e magnetita (?).

Magnetita/IImenita Basaltos Este tipo de rocha tem características semelhantes às anteriores e foi separado dos demais em função da quantidade de magnetita/ilmenita (ou titanomagnetita), que atinge até $20 \%$ modal.

Traquibasaltos As características gerais destes basaltos alcalinos são muito semelhantes aos demais, nos aspectos de campo e de amostra de mão, de maneira que só foi possível separá-los dos outros tipos através dos estudos petrográficos. Seu conteúdo mineralógico é definido basicamente por plagioclásio e titanaugita, entretanto, acham-se presentes sanidina em quantidades de até $10 \%$ modal. A sanidina forma microfenocristais tabulares, 
euédricos, de até $1,5 \mathrm{~mm}$ de comprimento, e são identificados finos intercrescimentos micropertíticos.

Metabasaltos Indistintamente, ao longo de todo o Gráben Jaibaras, os basaltos apresentam transformações hidrotermais relacionadas ao fraco metamorfismo que afetou a região. Os efeitos do metamorfismo nas rochas vulcânicas são mais visíveis nos locais em que elas estão intercaladas a ardósias, como na região de Santana do Acaraú, onde estão registrados além da foliação, forte cloritização e epidotização nos basaltos. Entretanto, no geral, as feições de metamorfismo não são evidentes em afloramento, e as transformações estão restritas à escala do mineral como saussuritização dos plagioclásios, substituição dos cristais de clinopiroxênio por tremolita-actinolita e clorita, além da presença de carbonato e clorita na matriz. Ademais, a presença de cristais radiais bem formados de epidoto e prehnita nas amígdalas, e discreta foliação nos basaltos, são evidências do metamorfismo regional que alcançou condições da fácies xisto verde baixo, nas rochas do Gráben Jaibaras.

ASPECTOS TEXTURAIS Os basaltos apresentam grande variação textural relacionada à posição que ocupam no leito do derrame. Destacam-se rochas com texturas porfirítica, seriada, afírica, vitrofírica e amigdaloidal.

A textura amigdaloidal demarca, preferencialmente, zonas superiores dos derrames facilitando a identificação no campo das sucessões dos leitos dos derrames. As amígdalas apresentam-se em formas subcirculares ou lenticulares, podendo estar alongadas e orientadas segundo a direção do fluxo dos derrames. Podem também apresentar formas irregulares entremeando-se nos interstícios dos minerais da matriz. As amígdalas estão preenchidas por minerais de baixa temperatura como clorita, zeólita, epidoto, quartzo, prehnita e carbonato. $\mathrm{O}$ interior das amígdalas é preenchido por cristais granulares ou radiais (Figs. $2 \mathrm{a} \mathrm{e} \mathrm{b}$ ), freqüentemente apresentando zoneamento composicional cujo núcleo, contendo clorita, é margeado por uma zona externa de cristais de epidoto. Pode ainda ocorrer casos em que os núcleos contendo carbonato são envolvidos por epidoto e clorita.

Texturas porfiríticas são comuns, destacando-se por vezes texturas glomeroporfiríticas com cumulados de plagioclásio e olivina (Figs. 2b e c). Nos tipos hipovítreos destacam-se fenocristais de plagioclásio com textura tipo peneira (sieve texture), numa matriz com grande quantidade de vidro ou material criptocristalino, provavelmente desvitrificado, nos quais acham-se mergulhados cristais de plagioclásio com formas aciculares e do tipo rabo de andorinha (swallowtail texture) e que também, estão associados cristais aciculares e/ou esqueletais de titanaugita. Tais feições são indicativas de nucleação múltipla e crescimento rápido de cristais num processo de superesfriamento da lava basáltica, conforme descrito por Cox et al. (1979).

Os fenocristais de plagioclásio tipo peneira apresentam dimensões da ordem de 2 mm e estão fortemente corroídos, denotando aspecto esponjoso, cujos buracos, reentrâncias e engolfamentos são ocupados pela matriz vítrea junto com micrólitos aciculares de plagioclásio (Fig. 2d). Essas feições são indicativas de reações de corrosão magmática causadas por instabilidades das fases minerais precoces com o líquido residual diante das variações de $\mathrm{Pe} \mathrm{T}$ no processo magmático.

As texturas tipo rabo de andorinha são identificadas nos micrólitos de plagioclásio mergulhados em material vítreo na matriz dos basaltos. Os cristais apresentam terminações afiladas ou ramificadas em segmentos duplos ou esqueletos de cristais (Figs. 2e e f). Por outro lado, formas esqueletais, em cristais aciculares ou prismáticos de clinopiroxênio, magnetita/ilmenita e olivina (Figs. $2 \mathrm{f}$, g e h), estão presentes com freqüência nos basaltos e, por sua associação com material vitreo, sugerem uma fase de superesfriamento (quenching) em determinados estágios deste magmatismo, em ambiente superficial.

QUÍMICA MINERAL O estudo petrográfico em rochas vulcânicas tem suas limitações devidas fundamentalmente ao tamanho pequeno dos grãos e à cristalinidade (basaltos hipocristalinos/ hipovítreos) o que dificulta a caracterização e a quantificação mineralógica e, consequentemente, a classificação das rochas. Por este motivo o quimismo de minerais e rochas torna-se ferramenta importante no estudo petrológico deste tipo de rocha. No caso dos basaltos estudados houve um agravante que diz respeito às alterações, comuns à maioria dos minerais, elevando a um grau de dificuldade maior o estudo petrográfico destes basaltos. As análises por microssonda eletrônica de minerais, neste caso, foram de grande importância para conferir os minerais previamente identificados por meios óticos e assim permitiram caracterizar e classificar com maior precisão os espécimes minerais e suas variações.

Análises em minerais de 12 amostras dos três tipos de basaltos (labradorita/andesina basalto, traquibasalto, magnetita/ilmenita basalto) foram realizadas no Laboratório de Microssonda Eletrônica da Universidade de Brasília, no equipamento CAMECA SX50, e os resultados são apresentados nas Tabelas 1,2 e 3 .

Plagioclásio Fenocristais e micrólitos de plagioclásio foram analisados em 5 amostras de basalto. Os dados da Tabela 1 e o diagrama de Deer et al. (1996), (Fig. 3) permitem evidenciar duas populações principais, uma de composição labradorita sódicaandesina cálcica $\left(\mathrm{An}_{44.55}\right)$ e outra de composição da albita $\left(\mathrm{An}_{0.3 .}\right.$. ${ }_{8,4}$ ). Pela análise destes dados verifica-se que, em geral, os plagioclásios mais cálcicos estão presentes indistintamente nos três tipos de basaltos analisados, tanto como fenocristais como na matriz (Tabela 1), e devem representar cristais magmáticos, e que veio confirmar os estudos de microscopia ótica. Entretanto, em alguns casos confirmou-se também a presença de albita.

Os traquibasaltos, por outro lado, apresentam cristais de albita extremamente sódica $\left(\mathrm{An}_{0,5-2}\right)$ sugerindo também uma origem primária para estes minerais, o que está refletido nas composições mais sódicas destas rochas.

A identificação de análises isoladas de albita associadas a plagioclásios cálcicos, dirige a interpretação de que uma parte dos cristais de albita devem ser produtos do metamorfismo de baixo grau que afetou a região.

Álcali-feldspato As análises de álcali-feldspatos foram obtidas em traquibasaltos, seja em fenocristais ou micrólitos da matriz (Tabela 2). No diagrama da figura 3 eles plotam predominantemente próximo ao vértice $\mathrm{OR}$, apontando composições extremamente potássicas $\left(\mathrm{Or}_{94.98}\right)$. Entretanto, duas análises fugiram deste padrão, plotando no campo do Anortoclásio e no limite AnortoclásioSanidina $\left(\mathrm{Or}_{37}\right)$, sugerindo representarem fenocristais primários de composição homogênea (não exsolvidos). Em outros casos foram identificados cristais com intercrescimento micropertítico, cujas lamelas analisadas identificaram composições de albita associadas aos álcali-feldspatos.

Clinopiroxênio O clinopiroxênio foi analisado em três amostras 

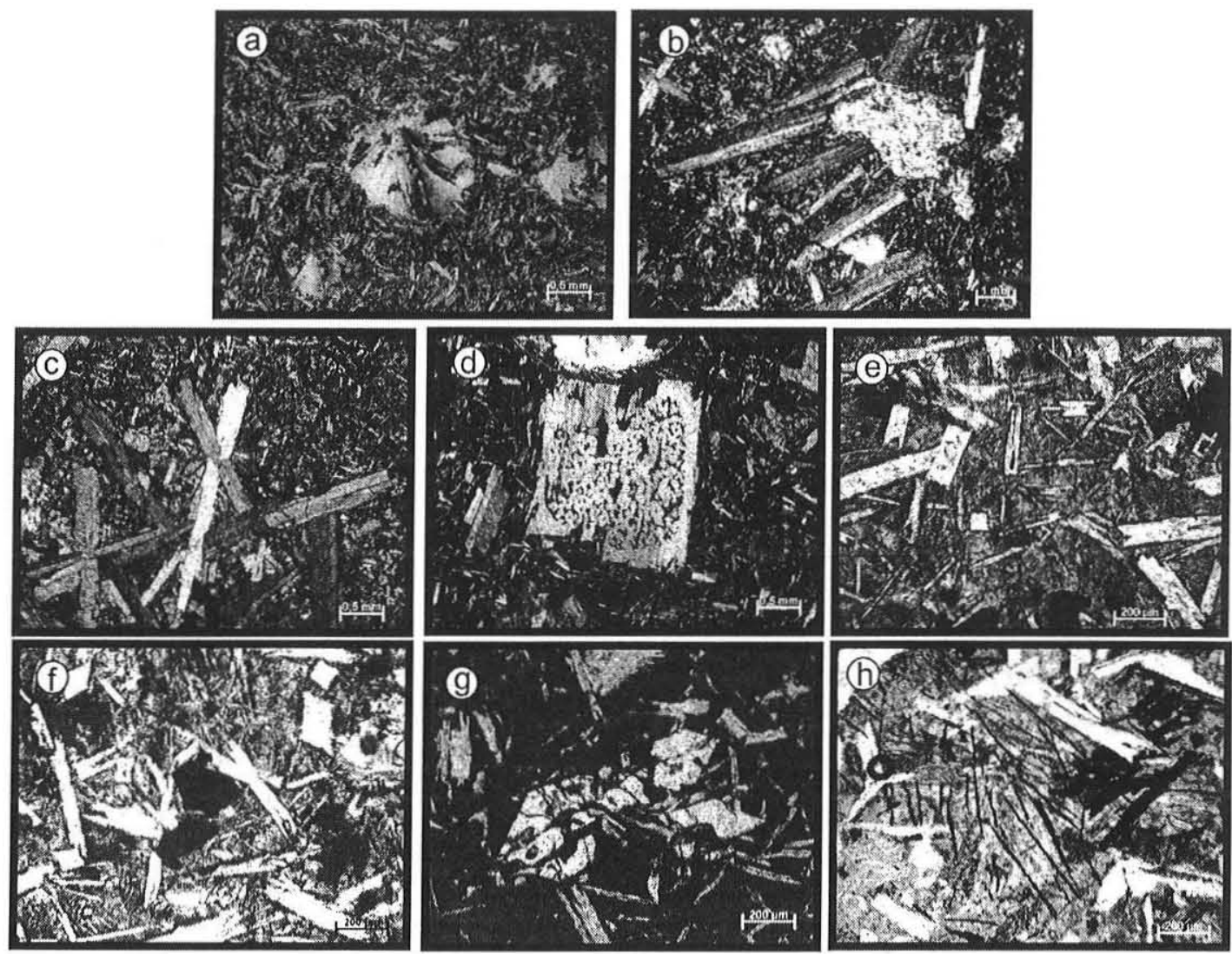

Figura 2 - Aspectos microtexturais dos basaltos da Suite Parapui: a) amigdala preenchida por cristais radiais de epidoto (NX, amostra ESA-V-36);b) amígdala preenchida por agregados granulares de zeólita em basalto porfirítico (NX, amostra EM-I-64.b); c) cumulados de fenocristais de plagioclásio em matriz intergranular; d) fenocristal de plagioclásio com textura tipo peneira; $e, f)$ cristais aciculares esqueléticos de plagioclásio com textura tipo rabo de andorinha, e clinopiroxênio em matriz desvitrificada; $\mathrm{g}$ ) cristal esquelético de olivina em matriz vítrea, cristalizado em condições de superesfriamento; $i)$ cristais aciculares de ilmenita cristalizado em condições de superesfriamento.

Tabela I - Análises químicas de plagioclásios e fórmula estrutural (na base de 32 oxigênios) dos basaltos da Suite Parapui.

\begin{tabular}{|c|c|c|c|c|c|c|c|c|c|c|c|c|c|c|c|c|c|c|}
\hline & 1 & 2 & 3 & 4 & 5 & 6 & 7 & 8 & 9 & 10 & 11 & 12 & 13 & 14 & 15 & 16 & 17 & 18 \\
\hline & $F$ & $M$ & $\mathrm{~F}$ & $\mathrm{~F}$ & $\mathrm{~F}$ & $M$ & F & F & M & M & $\mathrm{F}$ & $F$ & $\mathrm{~F}$ & $\mathrm{~F}$ & $\mathrm{~F}$ & M & $\mathrm{F}$ & $\mathrm{F}$ \\
\hline & $\mathrm{n}$ & & b & b & $\mathrm{n}$ & & b & $\mathrm{n}$ & & & b & $\mathrm{n}$ & b & b & b & & b & $\mathrm{n}$ \\
\hline $\mathrm{iO}_{2}$ & 67,58 & 67,11 & 68,50 & 3,62 & 53,47 & 54,77 & 54,77 & 53,77 & 54,16 & 65,22 & 54,99 & 54,47 & 66,07 & 55,14 & 69,30 & 65,62 & 68,05 & 67.91 \\
\hline & 20,30 & .58 & 19,47 & .42 & & 27. & 28,05 & 3,43 & & & 10 & & & & 19,67 & & & 9,13 \\
\hline & & & 23 & .04 & 11,23 & 10,34 & 10,58 & 11,30 & 10,70 & 1,9 & 10,80 & 11,37 & 0,8 & 10, & 0,00 & 0 , & 0 , & 0,34 \\
\hline & & & & & & & & & & & & & & & 0,00 & 0 & 0,0 &, 00 \\
\hline & 0,5 & & 0,13 & 2,76 & 0.38 & 0,3 & 0.56 & 0,4 & 0,5 & 0,1 & 0.50 & 0,3 & 1,27 & 0,5 & 0,10 & $0,$. & 0,0 & 0,31 \\
\hline & & & & 0,22 & 0,18 & 0,2 & 0,02 & 0,04 & 0,13 & $0,0 \mathrm{C}$ & 0,00 & 0,00 & 0,00 & 0,0 & 0,00 & 0.07 & 0,00 & 0,03 \\
\hline & & & & & & & & & & & & & & & 0,00 & 0, & 0,00 & 0,08 \\
\hline & 11,64 & & & & & & & & & & & & & & 10,30 & & & \\
\hline $\mathrm{K}_{2} \mathrm{O}$ & & & & & & & 0,49 & 0,45 & 0 & 0 , & 48 & 0 & & 0.4 & .07 & 1,36 & & \\
\hline Tot & 100,55 & 4 & 1 & & & & 99 & & & & & 100,10 & 101,18 & 100,94 & 9,44 & 99,29 & .23 & \\
\hline & & 96,8 & & & & & & & & & & & & & & & & \\
\hline & & 89 & 22 & & & 4,06 & & & 91 & 3,3 & & & 6,67 & 2,6 & 0,40 & 7,7 & 0,84 & \\
\hline & 23 & 22 & 1,09 & ,68 & 54,38 & 50,34 & 51,45 & 5,44 & 52,91 & 9,51 & 52,60 & 54,64 & 4,16 & 51,17 & 1,00 & 3,47 & 1,57 & 1.55 \\
\hline & .803 & 11,882 & 11,963 & 857 & & 9,980 & 9,939 & 824 & 9,912 & 11,489 & 9,949 & 9,856 & 11,585 & 9,894 & 12,072 & 11,644 & 11,892 & 11,953 \\
\hline & & & & & & 5,944 & 996 & 117 & 6,027 & 574 & 5.987 & 6.068 & 4,368 & 6.032 & ,035 & 4,381 & 4,080 & 965 \\
\hline & & & & & & & & & & & & & & & & & & \\
\hline & & & & & & & & & & & & & & & & & & \\
\hline & & & & & & & & & & & & & & & & & & \\
\hline & 00 & 000 & 000 & 020 & 020 & 030 & 0,000 & 0,000 & 010 & & & & & & & 0,000 & & \\
\hline & 001 & & & 018 & & 015 & 0,005 & 0,000 & 000 & .007 & 0,000 & 0,005 & 0,013 & 0,000 & 0,000 & 0,008 & 0,004 & 0,005 \\
\hline & & & & & & & & & & & & & & & & & & \\
\hline K & & & & & & & 0,112 & 0,105 & 0,115 & 0,132 & 0,111 & 0,109 & 0,264 & 0,106 & 0,015 & 0,310 & 0.037 & 0,067 \\
\hline & 20,097 & 20,010 & 20,014 & 20,089 & 20,065 & 20,040 & 20,024 & 19,992 & 19,994 & 19,977 & 20,066 & 20,016 & 20,124 & 20,071 & 19,653 & 20,099 & 20,075 & 20,079 \\
\hline
\end{tabular}

Análises: 1 a 3 - amostra SJA-10A (basalto); 4 a 6 - amostra SMM-31A (Magnetita-ilmenita basalto); 7 a 8 - amostra SMM-44C (ferro basalto); de 10 a 12 - amostra SMM-30A(magnetita-ilmenita basalto); 13 - amostra MIRIM-1 (basalto); 14 - amostra ESA-V-7 (basalto); 15 - amostra SJA-02C; 16 a 18 amostra SMM-39. Legenda: M-Micrólito, E-Fenocristal (n-núcleo, b-borda). 
Tabela 2 - Análises químicas de álcali-feldspatos e fórmula estrutural, na base de 32 oxigênios dos basaltos da Suite Parapuí.

\begin{tabular}{lrrrrrrrrrrr}
\hline & $\mathrm{l}$ & 2 & 3 & 4 & 5 & 6 & 7 & 8 & 9 & 10 & 11 \\
\hline & $\mathrm{F}$ & $\mathrm{M}$ & $\mathrm{M}$ & $\mathrm{F}$ & $\mathrm{F}$ & $\mathrm{F}$ & $\mathrm{F}$ & $\mathrm{F}$ & $\mathrm{F}$ & $\mathrm{F}$ & $\mathrm{M}$ \\
& $\mathrm{b}$ & & & $\mathrm{n}$ & $\mathrm{b}$ & $\mathrm{b}$ & $\mathrm{b}$ & $\mathrm{n}$ & $\mathrm{b}$ & $\mathrm{n}$ & \\
\hline $\mathrm{SiO}_{2}$ & 64,57 & 64,43 & 64,57 & 65,77 & 64,82 & 68,44 & 64,97 & 64,86 & 64,90 & 64,60 & 63,33 \\
$\mathrm{Al}_{2} \mathrm{O}_{3}$ & 18,23 & 18,35 & 18,53 & 17,71 & 18,25 & 19,29 & 18,26 & 18,15 & 18,42 & 18,33 & 18,31 \\
$\mathrm{CaO}$ & 0,00 & 0,00 & 0,00 & 0,02 & 0,00 & 0,01 & 0,01 & 0,00 & 0,00 & 0,01 & 0,03 \\
$\mathrm{MnO}$ & 0,00 & 0,01 & 0,00 & 0,00 & 0,00 & 0,00 & 0,02 & 0,00 & 0,00 & 0,00 & 0,00 \\
$\mathrm{FeO}$ & 0,07 & 0,21 & 0,03 & 0,01 & 0,04 & 0,16 & 0,22 & 0,21 & 0,07 & 0,08 & 0,12 \\
$\mathrm{SiO}$ & 0,00 & 0,00 & 0,00 & 0,00 & 0,00 & 0,00 & 0,00 & 0,00 & 0,00 & 0,00 & 0,00 \\
$\mathrm{BaO}$ & 0,04 & 0,00 & 0,19 & 0,00 & 0,00 & 0,00 & 0,00 & 0,00 & 0,00 & 0,00 & 0,21 \\
$\mathrm{Na} \mathrm{H}_{2} \mathrm{O}$ & 0,43 & 0,24 & 0,69 & 0,29 & 0,25 & 6,86 & 0,23 & 0,27 & 0,38 & 0,26 & 1,08 \\
$\mathrm{~K} \mathrm{O}$ & 16,42 & 16,50 & 16,17 & 15,94 & 16,48 & 6,18 & 16,37 & 16,61 & 16,47 & 16,38 & 14,88 \\
\hline $\mathrm{Total}$ & 99,76 & 99,74 & 100,18 & 99,74 & 99,84 & 100,94 & 100,09 & 100,09 & 100,24 & 99,66 & 97,95 \\
\hline $\mathrm{AB}$ & 3,85 & 2,17 & 6,09 & 2,70 & 2,20 & 62,60 & 2,10 & 2,40 & 3,40 & 2,30 & 43,55 \\
$\mathrm{OR}$ & 96,15 & 97,81 & 93,91 & 97,20 & 97,80 & 37,10 & 97,80 & 97,60 & 96,60 & 97,60 & 2,92 \\
$\mathrm{AN}$ & 0,00 & 0,02 & 0,00 & 0,10 & 0,00 & 0,30 & 0,10 & 0,00 & 0,00 & 0,10 & 53,53 \\
\hline $\mathrm{Si}$ & 11,975 & 11,970 & 11,944 & 12,143 & 12,008 & 12,047 & 12,008 & 12,008 & 11,983 & 11,992 & 11,933 \\
$\mathrm{Al}$ & 4,007 & 4,014 & 4,037 & 3,850 & 3,981 & 3,998 & 3,976 & 3,957 & 4,006 & 4,006 & 4,064 \\
$\mathrm{Ca}$ & 0,000 & 0,001 & 0,000 & 0,004 & 0,000 & 0,011 & 0,003 & 0,000 & 0,002 & 0,002 & 0,007 \\
$\mathrm{Mn}$ & 0,000 & 0,001 & 0,000 & 0,000 & 0,000 & 0,000 & 0,003 & 0,000 & 0,000 & 0,000 & 0,000 \\
$\mathrm{Fe}$ & 0,011 & 0,033 & 0,050 & 0,010 & 0,006 & 0,023 & 0,000 & 0,033 & 0,012 & 0,013 & 0,018 \\
$\mathrm{Sr}$ & 0,000 & 0,000 & 0,000 & 0,000 & 0,000 & 0,000 & 0,000 & 0,000 & 0,000 & 0,000 & 0,000 \\
$\mathrm{Ba}$ & 0,030 & 0,000 & 0,014 & 0,000 & 0,000 & 0,000 & 0,000 & 0,000 & 0,000 & 0,000 & 0,015 \\
$\mathrm{Na}$ & 0,156 & 0,087 & 0,247 & 0,103 & 0,088 & 2,340 & 0,084 & 0,097 & 0,135 & 0,093 & 0,393 \\
$\mathrm{~K}$ & 3,885 & 3,911 & 3,816 & 3,755 & 3,901 & 1,387 & 3,860 & 3,923 & 3,880 & 3,879 & 3,576 \\
\hline $\mathrm{Total}$ & 20,064 & 20,017 & 20,108 & 19,865 & 19,984 & 19,806 & 19,934 & 20,018 & 20,018 & 19,985 & 20,006
\end{tabular}

Análises 1 a 10 - amostra SJA-02C (traquibasalto);

Análise 11 - amostra SMM-39 (fragmento de traquibasalto em rocha vulcanoclástica).

M-micrólito; F-fenocristal (n-núcleo, b-borda).

de labradorita/andesina basaltos em cristais presentes na matriz (Tabela 3). Tem composição bastante homogênea, sendo rico em $\mathrm{CaO}(18-21 \%), \mathrm{FeO}(12-16 \%)$ e $\mathrm{MgO}$ (9-14\%). Utilizando o sistema classificatório de Morimoto (1988) (Fig. 4)os piroxênios são do tipo cálcico, situando-se no campo da augita cálcica com algumas amostras projetando-se ao campo do diopsídio-hedembergita (WO

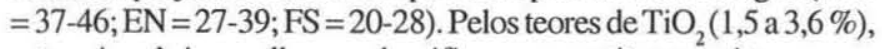
estes piroxênios melhor se classificam como titanoaugita.

LITOQUÍMICA Da amostragem total feita no Gráben Jaibaras 23 amostras dos basaltos foram escolhidas para a dosagem dos elementos maiores e traços, incluindo os ETR (Fig. 1, Tabela 4). As análises foram realizadas no Laboratório Lakefield-Geosol Ltda. por Fluorescência de Raio-X para os elementos maiores e traços, Titulometria para dosagem de FeO, Perda ao Fogo (calcinação a $1000^{\circ} \mathrm{C}$ ) e Espectrometria de Plasma (ICP) para os ETR.

Em geral os basaltos destacam-se pelo conteúdo de $\mathrm{SiO}_{2}$ entre 46 e $51 \%$ em peso, altos teores de álcalis $\left(4-7 \%\right.$ ), com razão $\mathrm{Na}_{2} \mathrm{O}$ / $\mathrm{K}_{2} \mathrm{O}$ alta, de $\mathrm{TiO}_{2}(2-4 \%)$ e $\mathrm{P}_{2} \mathrm{O}_{5}(0,5-2 \%)$. $\mathrm{CaO}$ e FeO total $_{\text {variam }}$ entre $5-8 \%$ e $10-14 \%$, respectivamente. Cálculos normativos CIPW revelam a presença de quartzo $(<12 \%)$ e hiperstênio (até 21 $\%$ ), ausência de olivina e nefelina normativos, e valores variados de albita $(\sim 13-41 \%)$ e anortita ( 14 - $43 \%)$. Valores normativos também elevados são registrados em magnetita (5-12\%), ilmenita (3-7\%) e apatita (1-15\%).

Os três principais tipos composicionais identificados petrograficamente (Labradorita/Andesina Basaltos, Traquibasaltos e Ilmenita/Magnetita basaltos) revelam também distinções nas suas características geoquímicas. Os traquibasaltos (análises 6, 8 e 10, Tabela 4) diferenciam-se dos labradorita/andesina basaltos pelos teores mais elevados de álcalis $(5,2$ a $6,5 \%)$ e TiO $_{2}(2,6$ a $3 \%)$ e mais baixos em $\mathrm{MgO}$; e os magnetita/ilmenita basaltos pelos altos teo-
Tabela 3 - Composição química e fórmula estrutural (na base de 6 oxigênios) dos clinopiroxênios dos basaltos da Suíte Parapuí.

\begin{tabular}{|c|c|c|c|c|c|c|c|c|c|c|}
\hline & 1 & 2 & 3 & 4 & 5 & 6 & 7 & 8 & 9 & 10 \\
\hline $\mathrm{SiO}_{2}$ & 48,66 & 48,04 & 49,63 & 47,03 & 46,49 & 47,85 & 48,83 & 49,36 & 49,98 & 48,71 \\
\hline & 2,54 & 2,30 & 2,55 & 2,90 & 3,61 & 2,44 & 2,43 & & & \\
\hline & 3,21 & & 4,22 & & & & & & & \\
\hline & 13,86 & 12,32 & 13,55 & 11,44 & 14,20 & 15,92 & $|4,4|$ & 14,53 & 12,70 & \\
\hline $\mathrm{O}_{3}$ & & 0,00 & & & 0,00 & 0,00 & 0,00 & 0.00 & 0,00 & \\
\hline & & & & & 0,0 & 0,00 & 0 & 0 , & & \\
\hline & 0 , & 33 & 0,36 & 0,3 & 0,30 & 0,41 & 0,70 & 0,39 & 0,33 & 0,32 \\
\hline & 0 & 00 & 0 , & 0 & 0 & 0,00 & 0,00 & 0 , & 0 , & \\
\hline & 1 & 12,45 & 8,69 & 10, & 9,7 & 9,39 & 54 & 13, & & \\
\hline & ,02 & 19,42 & 19,77 & 20,7 & 21,00 & 20,22 & 19, & 17. & & \\
\hline & 0,10 & $0, \mathrm{C}$ & 0,44 & & & & & & 0 , & \\
\hline & 0,00 & & 0, & & 12 & & 08 & ,00 & 0,00 & 0,02 \\
\hline Total & 99,66 & 98,01 & 99,88 & 100,16 & 99,38 & 99 , & 99,50 & 99,32 & 99,72 & 02 \\
\hline & 1,87 & 1,86 & 1,91 & & 1,80 & & & & & \\
\hline & & & & & & & & & & \\
\hline & & & & & 00 & & & 0 & & 00 \\
\hline & 0,01 & 0,00 & 0 , & & 00 & 0,00 & 03 & & & 00 \\
\hline & 0,07 & 0,07 & 0,07 & 0 . & 0,11 & 0,07 & 0,07 & 0,04 & 0,06 & 0,06 \\
\hline & 0,03 & 0,00 & 0 , & 0 , & 0,00 & 0,00 & 0,00 & 0,00 & 0,00 & 0,00 \\
\hline & 0,20 & 0,21 & 0 & & . & 0,39 & 35 & 0,20 & 0,19 & 0,31 \\
\hline & 0 , & & & & D & & 00 &, 00 & 0, & 00 \\
\hline & & & & & & & 55 & .76 & 0,7 & 63 \\
\hline & & & & & & & & & & \\
\hline & & & & & & & & & & \\
\hline & & & & & & & & & & \\
\hline & 0,01 & 0,01 & & & 01 & 0,01 & 0,02 & 01 & 0,0 & \\
\hline & 0,74 & 0,81 & & & 87 & 0,84 & 0,83 & 0,73 & 0,77 & 0,83 \\
\hline & 0,01 & 0,0 & & & 01 & 0,02 & 0,03 & 0,00 & 0,01 & 0,01 \\
\hline & & 0,00 & & & 01 & 0,00 & 0,00 & 0,00 & 0,00 & 0,0 \\
\hline & 00 & 4,00 & 3,98 & & 3,99 & 4,00 & 4,00 & 4,00 & 4,00 & 4,00 \\
\hline & & & & & & & & & & \\
\hline & & & & & & & & & & \\
\hline & & & & 26,04 & 24,69 & & & & 21,38 & 24.27 \\
\hline
\end{tabular}

Análises 1 e 2 - amostra SMM-44C; Análises 3 a 7 - amostra MU-P-33A, Análises 8 a 10 - amostra Mirim 1 .

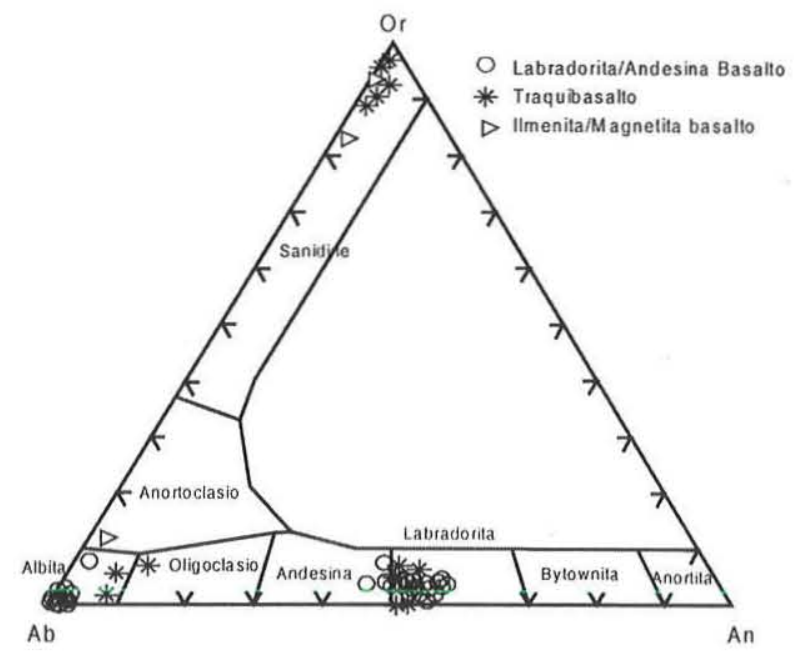

Figura 3 - Diagrama Ab-An-Or com a plotagem das análises de plagioclásio e alcalifeldspato dos basaltos da Tabela 1 e 2 .

res de $\mathrm{FeO}_{\text {Total }}(17 \%), \mathrm{TiO}_{2}(4 \%), \mathrm{P}_{2} \mathrm{O}_{5}(2 \%), \mathrm{K}_{2} \mathrm{O}(3 \%)$, e mais baixos teores de $\mathrm{SiO}_{2}(43 \%)$ em relação aos outros tipos.

No diagrama de multi-elementos em geral os basaltos têm assinatura geoquímica semelhante, sendo que o traquibasalto tem concentrações levemente mais elevadas da maioria dos elementos (Fig. 5). A amostra Ararius l destaca-se pelos seus teores mais baixos de K, Rb, Sr e Ba, e mais elevados em Ti, Ca, Na e P.

No diagrama AFM (Fig. 6), os basaltos situam-se no campo da 


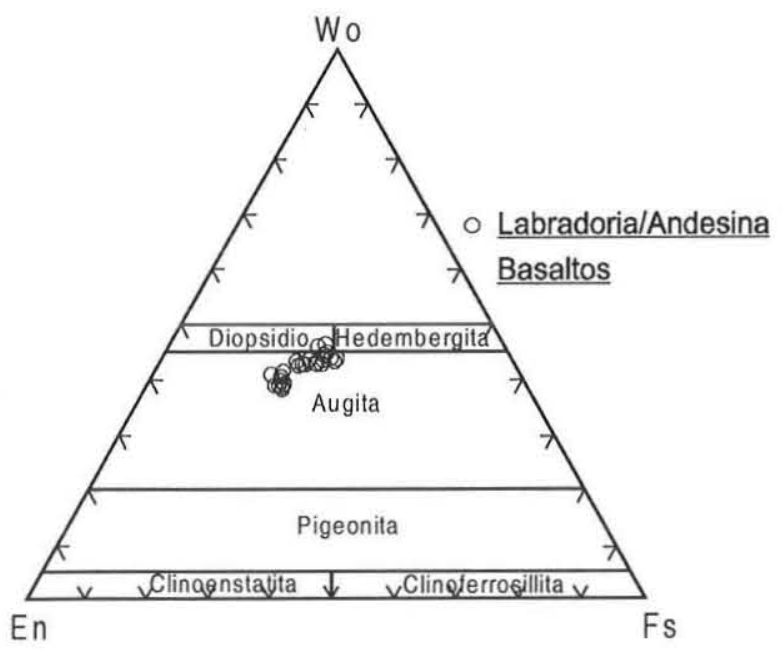

Figura 4 - Diagrama de Morimoto (1988) apresentando o domínio ocupado pelos clinopiroxênios dos basaltos da Tabela 3.

Serie Toleiítica, com trend de diferenciação.No diagrama TAS de Le Maitre et al. (1989), as amostras situam-se nos campos de basalto toleiítico, basaltos alcalinos e traquibasaltos, e uma amostra (SMM-31) situa-se no campo de tefrito. No diagrama $R_{1}-R_{2}$ de La Roche et al. (1980) e de elementos traços de Winchester \& Floyd (1977), o comportamento é semelhante (Fig. 7). Inserindo a curva separadora de séries magmáticas de Irvine \& Baragar (1971) no diagrama TAS (Fig. 7) verifica-se que a maioria das amostras ocupam o campo subalcalino e as restantes, incluindo os traquibasaltos, situam-se pouco acima da curva divisória, no campo alcalino.

O comportamento dos ETR (Fig. 8) também reflete a homogeneidade composicional das amostras, desenhando padrão inclinado, com marcante enriquecimento em ETR leves, bem fracionado $\left(\mathrm{La} / \mathrm{Yb}_{\mathrm{N}}\right.$ elevada $\left.=10-22\right)$, e pequena anomalia negativa de $\mathrm{Eu}(0,5-0,7)$.

Considerando o conjunto dos dados, interpreta-se que as rochas estudadas representam basaltos da série transicional, tendo os traquibasaltos como representantes mais evoluídos.

Utilizando diagrama de paleoambiência de Pearce \& Norry (1979), permite interpretá-los como basaltos tipo intraplaca continental (Fig. 9), estando de acordo com os estudos tectônicos executados na região (Gorayeb et al. 1988, Abreu et al. 1993, Quadros 1996) em que vinculam a implantação do Graben Jaibaras à tectônica extensional intracontinental, estabelecida na região no final do Neoproterozóico.

CONCLUSÕES A Suíte Parapuí representa remanescentes de um vulcanismo acontecido no final do Neoproterozóico que hoje resta embutido no Gráben Jaibaras em extensos derrames intercalados a seqüências sedimentares do Grupo Jaibaras ou como seixos, matacões e blocos nos conglomerados da Formação Aprazível, unidade considerada como representante dos últimos pulsos da tectônica na evolução do Gráben Jaibaras. A Suíte consiste de uma sucessão de derrames de basaltos, níveis restritos de riolitos e sucessivos depósitos piroclásticos ou epiclásticos, que se acham interpostos aos sedimentos imaturos do Grupo Jaibaras.

Ao longo do Gráben Jaibaras não se identificou andesitos, espilitos ou queratófiros, e geoquimicamente não condizem com

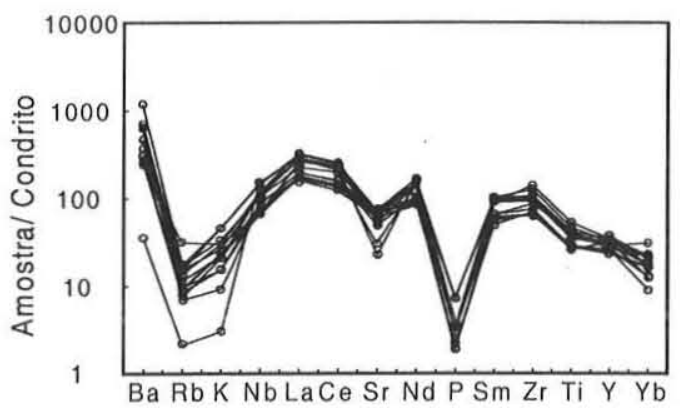

Figura 5 - Diagrama de multielementos dos basaltos da Suite Parapui, normalizados pelo padrão condrítico de Sun \& McDonough (1989).

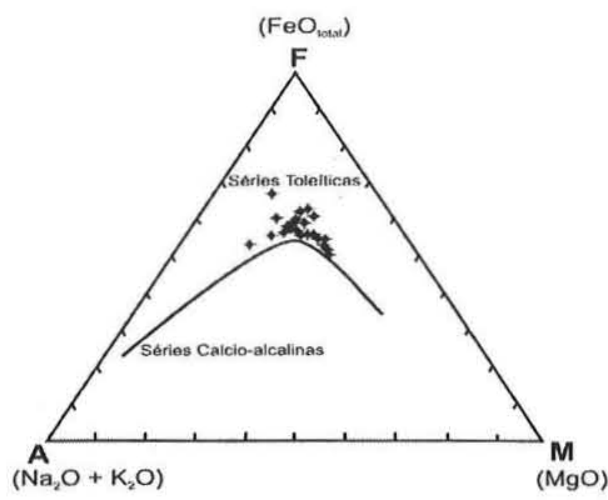

Figura 6 - Diagrama AFM com a curva divisória dos campos das séries cálcio-alcalinas e toleíticas de Irvine \& Baragar (1971) com a posição dos basaltos estudados.

suítes cálcio-alcalinas, contrapondo-se a Costa et al. (1979).

A análise petrográfica associada aos dados de campo e estudos químicos em rochas e minerais permite caracterizá-los como basaltos de série transicional. A presença de albita e sanidina, os teores levemente elevados de álcalis somados às características explosivas deste vulcanismo e ao ambiente tectônico de rifte permitem apontar para tendências mais alcalinas de parte deste vulcanismo.

Os depósitos piroclásticos com bombas, lápilis e cinzas de basaltos, representam evidências claras de fases explosivas deste magmatismo em condições subaéreas.

Finaimente a Suíte Parapuí, foi estabelecida através de um intenso vulcanismo durante a tectônica extensional de instalação da Bacia de Jaibaras no seu estágio rifte e representa um magmatismo intracontinental subaéreo com efusões e explosões.

Agradecimentos O presente trabalho foi desenvolvido no âmbito do "Projeto Cráton do São Luís e sua relação com a porção oeste da Província Borborema", financiado pela Financiadora de Estudos e Projetos (FINEP) com apoio do Centro de Geociências da Universidade Federal do Pará. Ao Prof. Dr. José Carlos Gaspar, pelo uso do Laboratório de Microssonda Eletrônica e à Fundação Coordenação de Aperfeiçoamento de Pessoal de Nível Superior (CAPES) pela concessão de bolsa de mestrado da autora, desenvolvido no Curso de Pós-Graduação em Geologia e GeoquímicaUFPA. Aos revisores da RBG pelas sugestões ao manuscrito. 

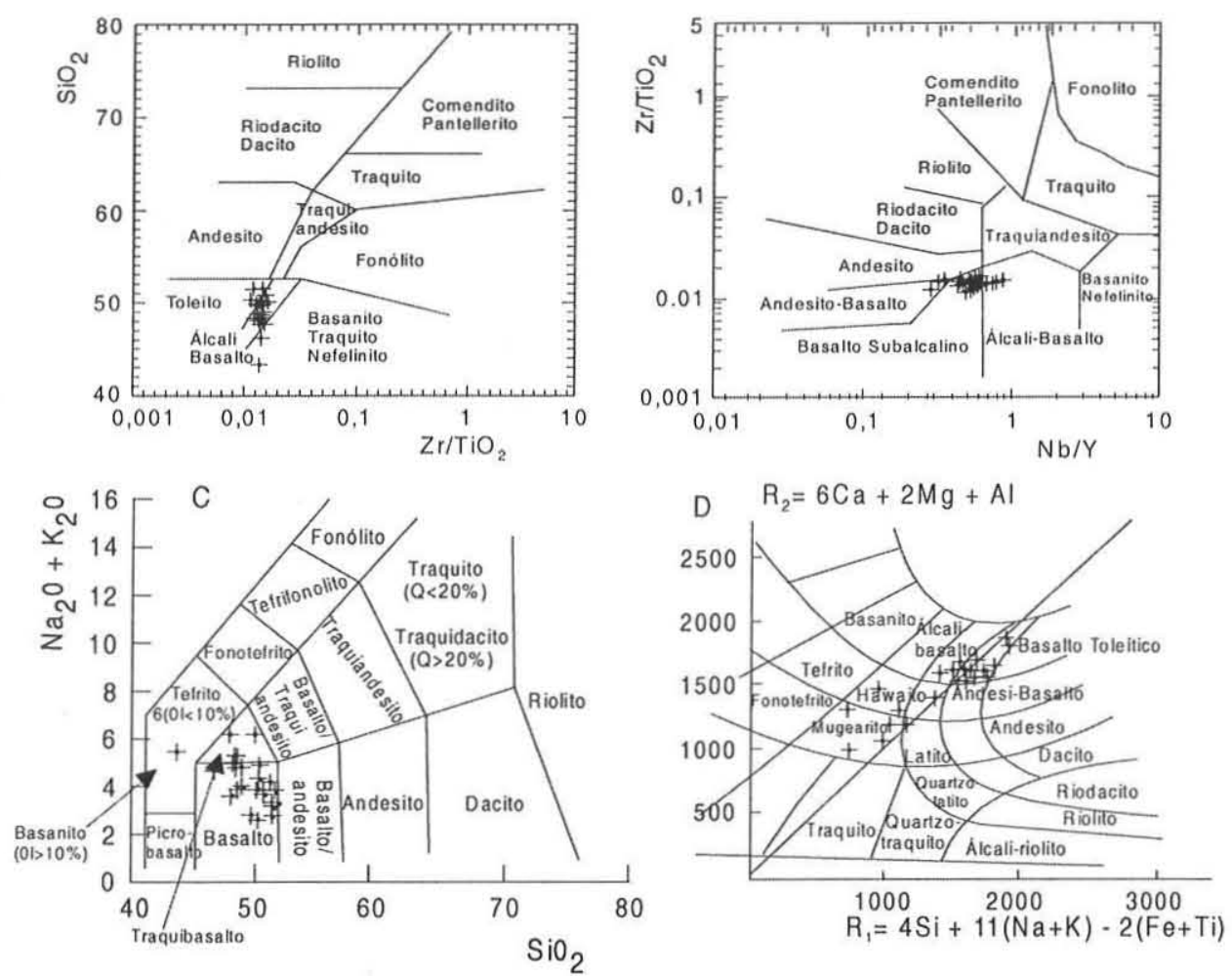

Figura 7 - Diagramas de classificação geoquímica com o posicionamento dos basaltos da Tabela 4: a, b) Diagrama de Winchester \& Floyd (1977); c) Diagrama TAS de Le Maitre et al. (1989) com a curva divisória das series alcalinas e subalcalinas de Irvine \& Baragar (1971); d) Diagrama RI-R2 de La Roche et al. (1980).

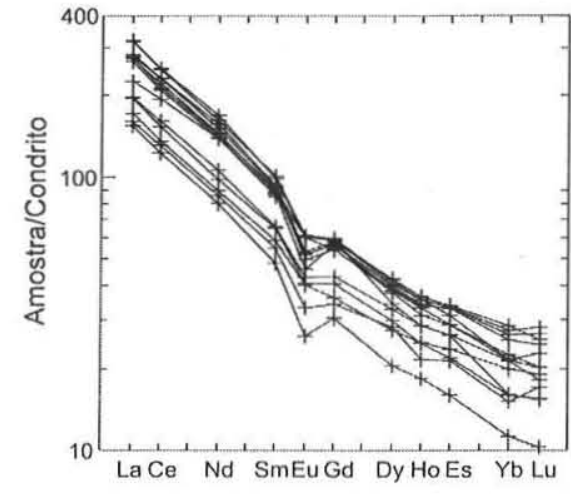

Figura 8 - Diagrama de ETR dos basaltos da Suite Parapuí, normalizados pelo condrito de Sun \& McDonough (1989).

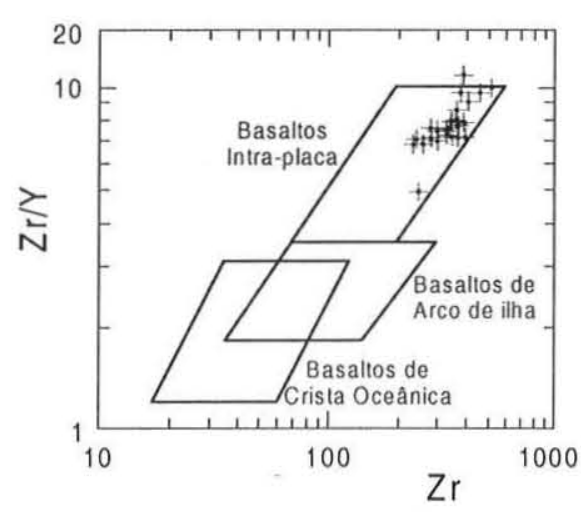

Figura 9 - Diagrama de classificação paleoambiental de basaltos de Pearce \& Norry (1979), com a posição dos basaltos estudados.

\section{Referências}

Abreu F.A.M., Gorayeb P.S.S., Gama Jr. T . 1989. Aspectos tectônicos da região de Martinópole-Massapê-CE. In: SBG, Simp. Geol. Nordeste, 13, Fortaleza, Atas, 265-267.

Abreu F.A.M., Gorayeb P.S.S., Gama Jr.T., Hasui Y. 1988. O Cinturão de Cisalhamento do Noroeste do Ceará. In: SBG. Congr. LatinoAmericano de Geologia, 35, Belém, Anais, 2:20-23.

Abreu F.A.M., Gorayeb P.S.S., Hasui Y. 1993. Grábens eopaleozóicos do oeste cearense - Considerações sobre as sequiências litoestratigráficas. In: SBG. Simp. Geol. Nordeste, 15, Natal, Atas, 13:29-31.

Costa M..J., França J.B., Lins C.A.C., Bacchiegga I.F.,Habekost C.R.,
Cruz W.B. 1979. Geologia da Bacia de Jaibaras, Ceará, Piauí e Maranhão- Projeto Jaibaras. Brasília, MME/DNPM. 106p. (Série Geologia Básica, 11).

Cox K.G., Bell J.D., Pankhurst R.J. 1979. The interpretation of igneous rocks. London. George Allen \& Unwin. 450p.

Deer W.A., Howie R.A., Zussman N J. 1966. An introduction to rock forming minerals. London. Longmans Group Ltd. 528p.

Gaudette H.E., Abreu F.A.M., Lafon M., Gorayeb P.S.S. 1983. Evolução tranzamazônica do Cinturão de Cisalhamento Noroeste do Ceará: novas evidências geocronológicas. In: SBG, Simp. Geol. Nordeste, 
Tabela 4 - Teores dos elementos maiores, menores (\% em peso), traços (ppm) e norma, das rochas basálticas da Suíte Parapuí (continua).

\begin{tabular}{|c|c|c|c|c|c|c|c|c|c|c|c|}
\hline & $\begin{array}{c}1 \\
\text { Mirim-1 }\end{array}$ & $\begin{array}{c}2 \\
\text { Mirim-2 }\end{array}$ & $\begin{array}{c}3 \\
\text { Arariús-1 }\end{array}$ & $\begin{array}{c}4 \\
\text { Arariús-2 }\end{array}$ & $\begin{array}{c}5 \\
\text { MU-P-33A }\end{array}$ & $\begin{array}{c}6 \\
\text { MU-P-35A }\end{array}$ & $\begin{array}{c}7 \\
\text { PA-P-02A }\end{array}$ & $\begin{array}{c}8 \\
\text { PA-P-02C }\end{array}$ & $\begin{array}{c}9 \\
\text { PA-P-04D }\end{array}$ & $\begin{array}{c}10 \\
\text { PAP-08D }\end{array}$ & $\begin{array}{c}11 \\
\text { PAP-20C }\end{array}$ \\
\hline $\mathrm{SiO}_{2}$ & 48,30 & 50,70 & 46,20 & 48,00 & 47,70 & 47,70 & 50,00 & 49,50 & 49,10 & 48,70 & 51,50 \\
\hline $\mathrm{TiO}_{2}$ & 2,60 & 2,00 & 3,40 & 2,60 & 1,70 & 3,00 & 2,50 & 2,90 & 2,00 & 2,60 & 1,70 \\
\hline $\mathrm{Al}_{2} \mathrm{O}_{3}$ & 15,00 & 14,70 & 14,00 & 15,00 & 14,60 & 15,40 & 15,00 & 14,40 & 15,00 & 14,80 & 15,30 \\
\hline $\mathrm{Fe}_{2} \mathrm{O}_{3}$ & 7,50 & 4,80 & 7,00 & 6,60 & 5,10 & 7,20 & 4,20 & 5,00 & 7,40 & 6,30 & 4,50 \\
\hline $\mathrm{FeO}$ & 6,00 & 7,00 & 5,30 & 7,00 & 6,60 & 6,00 & 7,90 & 5,00 & 5,00 & 7,00 & 6,00 \\
\hline $\mathrm{MnO}$ & 0,21 & 0,21 & 0,21 & 0,21 & 0,20 & 0,21 & 0,21 & 0,30 & 0.22 & 0,25 & 0,21 \\
\hline $\mathrm{MgO}$ & 4,70 & 5,40 & 4,70 & 4,60 & 7,40 & 4,20 & 4,20 & 3,00 & 4,80 & 5,00 & 6,00 \\
\hline $\mathrm{CaO}$ & 6,50 & 7,20 & 9,10 & 6,50 & 8,10 & 5,50 & 7,00 & 6,90 & 7,80 & 6,00 & 7,70 \\
\hline $\mathrm{Na}_{2} \mathrm{O}$ & 3,60 & 2,90 & 4,70 & $3,, 70$ & 3,00 & 4,40 & 2,10 & 4,40 & 3,30 & 3,60 & 2,00 \\
\hline $\mathrm{K}_{2} \mathrm{O}$ & 1,40 & 1,50 & 0,20 & 1,50 & 1,00 & 2,00 & 3,00 & 2,00 & 1,00 & 1,60 & 2,00 \\
\hline $\mathrm{P}_{2} \mathrm{O}_{5}$ & 0,93 & 0,60 & 2,00 & 0,95 & 0,50 & 1,30 & 1,00 & 0,88 & 0,52 & 0,92 & 0,50 \\
\hline P.F. & 2.30 & 2,00 & 2,42 & 2,37 & 3,27 & 2,28 & 1,92 & 4,92 & 3,22 & 2,31 & 1,69 \\
\hline TOTAL & 99,04 & 99,01 & 99,23 & 99,03 & 99,17 & 99,19 & 99,03 & 99,20 & 99,36 & 99,08 & 99,10 \\
\hline $\mathrm{Ba}$ & 897 & 878 & 87 & 944 & 759 & 1522 & 1477 & 704 & 1119 & 1009 & 628 \\
\hline $\mathrm{Rb}$ & 27 & 23 & 5 & 26 & 20 & 41 & 36 & 39 & 22 & 24 & 78 \\
\hline $\mathrm{Sr}$ & 427 & 400 & 160 & 399 & 424 & 506 & 429 & 214 & 531 & 391 & 471 \\
\hline $\mathrm{Nb}$ & 28 & 20 & 37 & 31 & 18 & 36 & 35 & 25 & 21 & 29 & 16 \\
\hline $\mathrm{Zr}$ & 371 & 304 & 469 & 379 & 249 & 417 & 402 & 383 & 282 & 374 & 245 \\
\hline $\mathrm{Y}$ & 44 & 44 & 49 & 35 & 51 & 46 & 57 & 40 & 40 & 50 & 35 \\
\hline $\mathrm{Cr}$ & 68 & 136 & 68 & 68 & 204 & 136 & 68 & 68 & 68 & 68 & 68 \\
\hline $\mathrm{Ni}$ & 79 & 79 & 79 & 79 & 158 & 79 & 79 & 79 & 79 & 79 & 79 \\
\hline v & 348 & 290 & 348 & 290 & 290 & 348 & 348 & 290 & 348 & 348 & 348 \\
\hline $\mathrm{La}$ & 66,13 & - & 64,75 & - & 38,70 & - & 74,22 & 52,87 & 46,26 & - & - \\
\hline $\mathrm{Ce}$ & 138,30 & - & 139,27 & - & 80,72 & - & 149,81 & 118,98 & 93,81 & - & - \\
\hline $\mathrm{Nd}$ & 69,80 & - & 75,24 & - & 40,01 & - & 71,73 & 64,98 & 45,70 & . & - \\
\hline $\mathrm{Sm}$ & 13,57 & - & 15,13 & - & 8,34 & - & 14,18 & 13,36 & 9,82 & - & - \\
\hline $\mathrm{Eu}$ & 3,45 & - & 3,50 & - & 1,94 & - & 3,02 & 2,70 & 2,36 & . & - \\
\hline Gd & 11,21 & - & 12,16 & - & 7,08 & - & 11,66 & 11,84 & 8,38 & - & - \\
\hline Dy & 9,72 & - & 8,66 & - & 7,15 & - & 10,03 & 10,23 & 7,50 & . & - \\
\hline Ho & 1,77 & - & 1,62 & - & 1,22 & - & 1,94 & 2,06 & 1,39 & - & - \\
\hline Er & 4,80 & - & 4,38 & $\cdot$ & 3,53 & - & 5,52 & 5,61 & 3,62 & - & - \\
\hline $\mathrm{Yb}$ & 3,66 & - & 2,73 & $\cdot$ & 2,57 & - & 4,30 & 4,64 & 2,72 & - & - \\
\hline Lu & 0,58 & - & 0,39 & - & 0,43 & $\cdot$ & 0,62 & 0,71 & 0,39 & - & - \\
\hline $\mathrm{Q}$ & 4,54 & 5,70 & 0,20 & 2,61 & 0,80 & 0,79 & 7,05 & 2,34 & 6,73 & 3,64 & 8,07 \\
\hline Or & 8,58 & 9,16 & 1,11 & 9,24 & 6,12 & 11,02 & 16,56 & 12,55 & 5,75 & 9,82 & 12,18 \\
\hline $\mathrm{Ab}$ & 31,52 & 25,30 & 41,25 & 32,55 & 24,74 & 38,49 & 18,41 & 39,44 & 29,15 & 31,57 & 17,40 \\
\hline An & 21,06 & 23,35 & 16,90 & 20,10 & 25,41 & 17,51 & 23,79 & 14,43 & 24,39 & 20.20 & 27,60 \\
\hline Di wo & 2,80 & 4,18 & 7,94 & 3,20 & 5,71 & 1,19 & 2,40 & 6,85 & 5.38 & 2,13 & 3,76 \\
\hline Dien & 2,31 & 2,72 & 6,85 & 2,31 & 4,02 & 0,98 & 1,36 & 5,46 & 4,64 & $1,49^{\circ}$ & 2.59 \\
\hline Di fs & 0,14 & 1,17 & - & 0,59 & 1,18 & 0,06 & 0,93 & 0,59 & - & 0,46 & 0,87 \\
\hline Hyen & 9,87 & 11,21 & 5,36 & 9,66 & 15,32 & 9,89 & 9,53 & 2,50 & 7,91 & 10,70 & 12,34 \\
\hline Hy fs & 0,61 & 4,80 & - & 2,47 & 4,50 & 0,63 & 6,54 & 0,27 & - & 3,30 & 4,15 \\
\hline $\mathrm{Mt}$ & 11,26 & 7,18 & 8,21 & 9,96 & 7,73 & 10,81 & 6,47 & 7,69 & 10,82 & 9,48 & 6,72 \\
\hline $\mathrm{He}$ & - & - & 1,40 & - & - & - & - & - & 0,27 & - & - \\
\hline II & 5,12 & 3,92 & 6,71 & 5,14 & 3,38 & 5,70 & 4,93 & 5,84 & 3,77 & 5,13 & 3032 \\
\hline Ap & 2,10 & 1,31 & 4,08 & 2,16 & 1,10 & 2,94 & 2,04 & 2,04 & 1,19 & 2,08 & 1,01 \\
\hline TOTAL & 99,91 & 100,00 & 100,01 & 99,99 & 100,01 & 100,01 & 100,01 & 100,00 & 100,00 & 100,00 & 100,01 \\
\hline $\mathrm{Na}_{2} \mathrm{O} / \mathrm{K}_{2} \mathrm{O}$ & 2,57 & 1,93 & 23.50 & 2,47 & 3,00 & 2,20 & 0,70 & 2,20 & 3,30 & 2,25 & 1,00 \\
\hline $\mathrm{Nb} / \mathrm{Y}$ & 0,63 & 0,45 & 0,75 & 0.88 & 0,35 & 0,78 & 0,61 & 0.62 & 0,52 & 0,58 & 0,45 \\
\hline $\mathrm{FeO}_{4}$ & 13,50 & 11,80 & 12,30 & 13,60 & 11,70 & 13,20 & 12,10 & 10,00 & 12,40 & 13,30 & 10,50 \\
\hline $\mathrm{Zr} ? \mathrm{TiO}_{2}$ & 143 & 152 & 138 & 146 & 252 & 139 & 161 & 132 & 141 & 144 & 144 \\
\hline
\end{tabular}

Análises 1 a 5, 7, 9, 11 a 21 - Basaltos; análises 6, 8, 10, 23 - Traquibasaltos; análise 21-Magnetita-ilmenita basalto.

15, Natal. Atas, 13:317-319.

Gorayeb P.S.S. \& Abreu F.A.M. 1989. A Faixa de Alto Grau de Cariré. In: SBG, Simp. Geol. Nordeste, 13, Fortaleza, Atas, 182-184.

Gorayeb P.S.S.\& Nascimento R.S. 1997. Rochas vulcânicas da Suíte Parapuí, Bacia de Jaibaras, CE: considerações geológicas e petrográficas. In: SBG Simp. Geol. Nordeste, 17, Fortaleza, Atas, 15:273-275.

Gorayeb P.S.S., Abreu F.A.M., Correa J.A.M., Moura C.A.V. 1988. Relações estratigráficas entre o Granito Meruoca e a Sequência UbajaraJaibaras. In: SBG, Congr. Bras. Geol., 35, Belém, Anais, 6:2678-2688.

Gorayeb P.S.S., Abreu F.A.M., Hasui Y. 1993. A tectônica distensiva e a geração de granitos eopaleozóicos no Noroeste do Ceará. In: SBG. Simp. Geol. Nordeste, 15, Natal, Atas, 13:254-257.
Irvine T.N. \& Baragar W.R.A. 1971. A guide to the chemical classification of the common volcanic rocks. Can. J. Earth Sci. 8:523-548.

La Roche H., Grandclaude P., Marchal M. 1980. A classification of volcanic and plutonic using $R_{1}-R_{2}$ diagram and major element analysis: its relationships with current nomenclature. Chem. Geol., 29:183-210.

Le Maitre R.W., Bateman P., Dudek A., Keller J., Lameyre E. , Le Bas M.J., Saabine P.A., Schimid R., Sorensen H., Streckeisen A., Wooley A.R.,Zanettin B. 1989. A classification of igneous rocks and glossary of terms-Recommendation of the IUGS. Oxford, Blackweel Scientific Publication. 193p.

Messshede M. 1986 A method of discriminating between different types of mid-ocean ridge basalts and continental tholeiites with the $\mathrm{Nb}-\mathrm{Zr}$ Y diagram. Chem. Geol., 56:1123-1133. 
Tabela 4 - Continuação.

\begin{tabular}{|c|c|c|c|c|c|c|c|c|c|c|c|c|}
\hline & $\begin{array}{c}12 \\
\text { ESA-III-4 }\end{array}$ & $\begin{array}{c}13 \\
\text { ESA-11-27 }\end{array}$ & $\begin{array}{c}14 \\
\text { ESA-V-7 }\end{array}$ & $\begin{array}{c}15 \\
\text { ESA-VII-6 }\end{array}$ & $\begin{array}{c}16 \\
\text { ESA-VII-10 }\end{array}$ & $\begin{array}{c}17 \\
\text { SPA-49 }\end{array}$ & $\begin{array}{c}18 \\
\text { SPA-50 }\end{array}$ & $\begin{array}{c}19 \\
\text { SPA-51 }\end{array}$ & $\begin{array}{c}20 \\
\text { SPA-53B }\end{array}$ & $\begin{array}{c}21 \\
\text { SPA-54A }\end{array}$ & $\begin{array}{c}22 \\
\text { SMM-31 }\end{array}$ & $\begin{array}{c}23 \\
\text { SMM-40B }\end{array}$ \\
\hline $\mathrm{SiO}_{2}$ & 50,20 & 50,00 & 51,10 & 51,50 & 48,00 & 48.00 & 49,80 & 49,60 & 48,30 & 50,30 & 43.30 & 48,10 \\
\hline $\mathrm{TiO}_{2}$ & 2,50 & 2,50 & 2,60 & 2,00 & 2,00 & 3,00 & 2,50 & 2,10 & 2,40 & 3.00 & 3,90 & 2,60 \\
\hline $\mathrm{Al}_{2} \mathrm{O}_{3}$ & 14,80 & 14,80 & 15,00 & 15,00 & 15,70 & 15,00 & 15,00 & 15,00 & 14,80 & 14,10 & 14,20 & 14.60 \\
\hline $\mathrm{Fe}_{2} \mathrm{O}_{3}$ & 6,00 & 7,00 & 6,10 & 3,60 & 6,30 & 7,10 & 6,60 & 6,60 & 5,10 & 5,80 & 10,70 & 8.00 \\
\hline $\mathrm{FeO}$ & 6,30 & 6,60 & 7,30 & 7,00 & 5,40 & 6.00 & 5,00 & 5.00 & 7,30 & 6,90 & 6,40 & 6.10 \\
\hline $\mathrm{MnO}$ & 0.21 & 0,20 & 0,20 & 0.21 & 0,23 & 0.16 & 0,12 & 0,12 & 0.13 & 0.19 & 0.20 & 0.22 \\
\hline $\mathrm{MgO}$ & 4,71 & 4,50 & 4,30 & 6,00 & 6,60 & 4,60 & 4,70 & 5.70 & 5,30 & 4,40 & 3,30 & 4,40 \\
\hline $\mathrm{CaO}$ & 7.90 & 7.00 & 7,00 & 7,70 & 7,20 & 7,00 & 7,10 & 8,10 & 8,00 & 7,60 & 7,60 & 6,30 \\
\hline $\mathrm{Na}_{2} \mathrm{O}$ & 2,00 & 2,00 & 2,10 & 2,00 & 3,10 & 3,10 & 2,30 & 3,60 & 3,00 & 2,80 & 2,70 & 4,00 \\
\hline $\mathrm{K}_{2} \mathrm{O}$ & 1.50 & 1,70 & 1,70 & 1,90 & 1,00 & 2,00 & 2,30 & 0,60 & 1,30 & 1,40 & 3,00 & 1,60 \\
\hline $\mathrm{P}_{2} \mathrm{O}_{5}$ & 0,80 & 0,90 & 0,90 & 0,50 & 0,50 & 0,95 & 0,90 & 0,60 & 0,80 & 0,82 & 2,00 & 1,00 \\
\hline P.F. & 2,21 & 1.80 & 2,00 & 1,63 & 3,00 & 2,22 & 1,80 & 2,00 & 2,17 & 1,70 & 1,77 & 2,00 \\
\hline TOTAL & 99,12 & 99,00 & 99,30 & 99,04 & 99,03 & 99,13 & 98,12 & 99,02 & 98,60 & 99,01 & 99,07 & 98,92 \\
\hline Ba & 1547 & 940 & 922 & 587 & 640 & 1724 & 1023 & 616 & 504 & 1145 & 2854 & 991 \\
\hline $\mathbf{R b}$ & 21 & 30 & 35 & 72 & 27 & 31 & 16 & 16 & 32 & 18 & 40 & 25 \\
\hline Sr & 475 & 341 & 380 & 475 & 536 & 453 & 423 & 423 & 438 & 358 & 518 & 405 \\
\hline $\mathrm{Nb}$ & 16 & 22 & 26 & 17 & 17 & 29 & 27 & 23 & 23 & 22 & 36 & 25 \\
\hline $\mathrm{Zr}$ & 353 & 334 & 371 & 237 & 283 & 395 & 345 & 264 & 301 & 332 & 527 & 357 \\
\hline Y & 50 & 47 & 48 & 35 & 38 & 51 & 46 & 39 & 41 & 45 & 53 & 45 \\
\hline $\mathrm{Cr}$ & 136 & 68 & 68 & 136 & 204 & 68 & 68 & 68 & 204 & 68 & 68 & 68 \\
\hline $\mathrm{Ni}$ & 79 & 79 & 79 & 79 & 79 & 79 & 79 & 79 & 79 & 79 & 79 & 79 \\
\hline v & 348 & 348 & 348 & 348 & 348 & 464 & 348 & 348 & 348 & 348 & 348 & 290 \\
\hline $\mathrm{La}$ & 62,01 & $\cdot$ & 62,63 & 40,49 & - & 75,92 & - & 36,78 & - & 46,67 & 65.69 & - \\
\hline $\mathrm{Ce}$ & 125,03 & $\cdot$ & 128,32 & 82,35 & - & 152,24 & $\cdot$ & 74,21 & - & 96,69 & 132,47 & $\cdot$ \\
\hline Nd & 63,90 & - & 66,43 & 41,54 & - & 77,64 & - & 37.47 & $\cdot$ & 48,90 & 66,79 & $\cdot$ \\
\hline $\mathrm{Sm}$ & 13,43 & $\cdot$ & 13,91 & 8,85 & - & 15,22 & - & 7,40 & - & 9.99 & 12,99 & $\cdot$ \\
\hline Eu & 2,86 & - & 3,00 & 2,32 & - & 3,04 & - & 1,53 & - & 2,49 & 3,12 & - \\
\hline Gd & 11.22 & $\cdot$ & 10.99 & 7,45 & - & 12,30 & - & 6,28 & - & 8.98 & 12,01 & - \\
\hline Dy & 9,81 & - & 6,61 & 6.99 & $\cdot$ & 10,59 & - & 5.20 & - & 8,33 & 10.68 & $\cdot$ \\
\hline Ho & 1,86 & $\cdot$ & 1,92 & 1.39 & $\cdot$ & 2,02 & - & 1,04 & - & 1.61 & 1.96 & - \\
\hline Er & 4.80 & - & 5,43 & 3,87 & - & 5,18 & - & 2,62 & - & 4,30 & 5.53 & - \\
\hline $\mathrm{Yb}$ & 3,81 & - & 4,48 & 3,40 & - & 3,59 & - & 1,92 & - & 6,65 & 4,84 & - \\
\hline Lu & 0,51 & $\cdot$ & 6,68 & 0,48 & - & 0.51 & $\cdot$ & 0,26 & - & 0,46 & 0,64 & - \\
\hline Q & 11,95 & 11,81 & 10,32 & 8,03 & 2.81 & 4,94 & 7,71 & 5,03 & 3,07 & 8,84 & 2,13 & 4,07 \\
\hline Or & 9,20 & 10,40 & 10,30 & 11,62 & 6,18 & 11,66 & 13,98 & 3,67 & 7,99 & 8.54 & 17,65 & 9,82 \\
\hline $\mathrm{Ab}$ & 13.53 & 17,49 & 18,17 & 16,61 & 27,37 & 27,18 & 19,97 & 31,43 & 26,34 & 24,39 & 23,48 & 32,46 \\
\hline An & 26,52 & 27,25 & 26,79 & 27.66 & 27,09 & 22,16 & 24,14 & 43,44 & 23,94 & 22,40 & 18.54 & 19.17 \\
\hline Di wo & 3,87 & 1,47 & 1,30 & 3.76 & 2,78 & 2,35 & 2,87 & 6,08 & 5,15 & 4,81 & 3.42 & 3,21 \\
\hline Di en & 2,82 & 1,08 & 0,88 & 2,35 & 2,20 & 2,41 & 2,04 & 5,16 & 3,39 & 3,29 & 2,95 & 2,61 \\
\hline Di fs & 0,69 & 0,25 & 0,32 & 1,18 & 0,27 & 0,17 & 0,57 & 0.11 & 5,39 & 1,13 & - & 0.21 \\
\hline Hy en & 9,37 & 10,56 & 11,67 & 12,65 & 15,04 & 9,52 & 10,03 & 9,56 & 10,38 & 8.05 & 5.54 & 8,81 \\
\hline Hy fs & 2,28 & 2,49 & 4,22 & 6.34 & 1,82 & 0.68 & 2,80 & 0,20 & 4.27 & 2.75 & - & 0,69 \\
\hline Mt & 9,02 & 10.35 & 9.06 & 5.40 & 9.54 & 10,68 & 9,09 & 9.89 & 7.68 & 8,67 & 10.22 & 11,74 \\
\hline $\mathrm{He}$ & - & - & - & - & - & - & - & : & - & 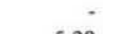 & 3,96 & - \\
\hline II & 4,93 & 4,91 & 5,06 & 3,34 & 3.77 & 5.52 & 4,88 & 4,12 & 4.74 & 5.29 & 7,62 & 5.13 \\
\hline Ap & 1,81 & 1,92 & 1,92 & 1,06 & 1,14 & 2,15 & 1,93 & 1,31 & 1,66 & 1.85 & 4,49 & 2,08 \\
\hline TOTAL & 99,99 & 99,98 & 100,01 & 100,00 & 100,01 & 100,02 & 100,01 & 100,00 & 100,00 & 100,01 & 100,00 & 100,00 \\
\hline $\mathrm{Na}_{2} \mathrm{O} / \mathrm{K}_{2} \mathrm{O}$ & 1,33 & 1,18 & 1,23 & 1,05 & 3,10 & 1,55 & 1,00 & 6,00 & 2,30 & 2,00 & 0,90 & 2,50 \\
\hline $\mathrm{Nb} / \mathrm{Y}$ & 0,32 & 0,47 & 0.54 & 0,48 & 0.45 & 0,57 & 0,59 & 0.60 & 0.56 & 0.49 & 0.68 & 0.54 \\
\hline $\mathrm{FeO}_{1}$ & 12.30 & 13,60 & 13.40 & 10,60 & 11.70 & 13.10 & 11,60 & 11,60 & 12,40 & 12,70 & 17,10 & 14,10 \\
\hline $\mathrm{Zr} / \mathrm{TiO}_{2}$ & 141 & 133 & 143 & 118 & 141 & 132 & 138 & 126 & 125 & 111 & 135 & 137 \\
\hline
\end{tabular}

Análises 1 a 5, 7, 9, 11 a 21 - Basaltos; análises 6, 8, 10, 23 - Traquibasaltos; análise 21- Magnetita-ilmenita basalto.

Morimoto N. 1988. Nomeclature of pyroxenes. Am. Mineral., 73:1123-1133.

Nascimento D.A., Gava A., Pires J.L., Teixeira W. 1981. Geologia da Folha SA-24 (Fortaleza)- Projeto RADAMBRASIL. Rio de Janeiro, MME/DNPM. 21:23-212.

Pearce J.A. \& Norry M.J. 1979. Petrogenetic implication of Ti, Zr, Y e $\mathrm{Nb}$ variations in volcanic rocks. Contrib. Mineral. Petrol., 69:33-47.

Pearce T.H., Gorman B.E., Birkett T.C. 1977. The relationship between major element chemistry and tectonic environment of basic and intermediate volcanic rocks. Earth Planet. Sci. Lett., 36:121-132.

Quadros M.L.E.S.1996. Estudo tectono-sedimentar da Bacia de Jaibaras, na região entre as cidades de Pacujá e Jaibaras, NW do Estado do Ceará. Belém. Dissertação de Mestrado, Universidade Federal do Pará, 134p.

Sá E.F.J., Hackspacher P.C., Nogueira A.M.M., McReath I., Lins F.A., Srivastava N.K.I. 1979. Observações sobre a estratigrafia e sequiências ígneas da Bacia de Jaibaras, Nordeste do Ceará. In: SBG, Simp. Geol. Nordeste, 9, Natal, Atas, 30-38.

Santos F.J. \& Neves B.B.B. 1984. Província Borborema. In: F.F.M. Almeida \& Y. Hasui (Eds), O Pré-Cambriano do Brasil. São Paulo, Edgard Blücher. 123-186.

Sun S.S. \& McDonough W.F. 1989. Chemical and isotopic systematics of oceanic basalts implications for mantle composition and processes. In: A .D. Saunders \& M.J Norry (Eds.) Magmatism in the ocean basins. Geological Society, Special Publication, 42:313-345.

Winchester J.A. \& Floyd P.A. 1977. Geochemical discrimination of different magma series and differentiation products using immobile. Chem. Geol., 20:325-343.

Manuscrito A-1390

Recebido em 28 de novembro de 2002 Revisão dos autores em 15 de setembro de 2004 Revisão aceita em 20 de setembro de 2004 